position of the wires and make-circuit lever, and tables of the results, and says, finally :-

"The simplicity and inexpensiveness of the chronoscope we have described in this paper, its accuracy, and the ease with which it is used, must commend it to all who will give it a trial under the conditions of the action which we have endeavoured to set forth in this paper. Another of its advantages is that its records on the paper covering the cylinder are easily rendered permanent by drawing the unsmoked side of the paper over the surface of a dilute solution of photographic negative varnish contained in a wide shallow dish. On the records may be written with a blunt style the nature of the experiments they record before the carbon is fixed by the varnish, and then they can be bound together in book-form for preservation and reference."

Alexander J. Ellis

\section{HINTS ON THE CONSTRUCTION AND EQUIPMENT OF OBSERVATORIES FOR AMATEURS}

I F it were necessary to offer any apology for the short series of articles of which the first is now presented to the readers of NATURE, it might be found in the fact that, so far as I know, nothing fulfilling the above title has been put into circulation in England for more than forty years. This is the more remarkable when one considers the great development of astronomy in this country during the present generation, a development the credit of which is far more due to amateur effort than to the influence of Governments or public establishments. The reason I have fixed upon the year I 844 is that that was the year in which Admiral Smyth published his wellknown "Bedford Catalogue of Celestial Objects," to which he prefixed certain chapters dealing with the construction and management of small observatories.

Those chapters have never been reproduced in any form, partly, no doubt, for the reason that they are a good deal out of date; but they are still capable of furnishing many useful hints to any one who wishes to write on the subject of observatories.

It is not too much to say that the Bedford Observatory has directly or indirectly served as the model for nearly all the private observatories of moderate dimensions since erected in England, and it is equally certain that, whatever may be the changes which considerations of finance, or architecture, or geology, may render expedient in particular instances, no important alterations need be made in the main features of the Bedford Observatory, although upwards of half a century has elapsed since it was erected, and more than forty years have passed away since it was pulled down.

In order to compress as much information as possible into a small compass I propose to classify what I have to say in such a way as shall successively conduct the reader step by step through the stages which he himself will have to pass through between the time when he determines to erect an observatory and the time when he finds himself the happy possessor of the completed building. Of telescopes as such I shall here say nothing, and the only other prefatory remark which seems requisite is this: that an amateur astronomer with only a given and moderate sum of money to lay out will do well to appropriate an adequate part of his funds to the purchase of a fairly good stand and of a suitable structure in which to house his instruments, rather than spend too much on his tube and then be obliged to starve the stand and to put up with inadequate shelter from the weather or no shelter at all. To begin, therefore, at the beginning.

The Choice of $a$ Site.-As to this the amateur will probably in most cases be obliged to suit himself as best he can. If his garden offers any varieties of site, he should endeavour to secure one on slightly rising ground, with an uninterrupted horizon to the south (for meridian purposes) and to the west (for comets and inferior planets in the vicinity of the sun at sunset). A clear horizon to the east is of less moment, unless searches for comets before sunrise are intended to be systematically carried out.

In making preparations for building an astronomical observatory-and occasionally, indeed, for other purposes -it is necessary to know how to set out a meridian line. Of course this may be done by means of a mariner's compass (correcting for the magnetic deviation); but there are other ways of doing this independently of a compass, and as it is not always easy to ascertain the deviation a statement of at any rate one of these other ways, as given by Challis, will be useful. Set up a pole at the spot through which the proposed meridian line is required to pass, using a plumb-line to ensure the pole being vertical. Draw around the pole as a centre several concentric horizontal circles, and mark the points of coincidence of the extremity of the shadow of the pole with these circles both before and after noon. Then if the two points on each circle be joined by a chord the mean of the directions of the middle points of the chords from the pole will be approximately the direction of the meridian line. This method answers best about midsummer when the sun's diurnal path is high in the heavens, and the change of declination is small. A little forethought must be displayed in suiting the dimensions of the circles to the height of the vertical pole employed.

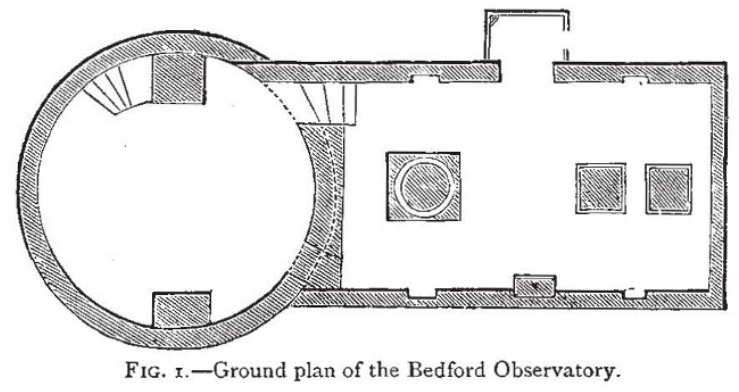

Foundations. - The foundations of an observatory are a matter of great importance, and unless a rock ${ }^{1}$ or chalk bottom can be readily obtained, an artificial bottom of concrete, more or less thick according to the height of the intended superstructure, must be made. This of course applies to the piers which are to carry instruments. In the case of the observatory itself, especially if the material of the fabric is to be of wood, which is so often used, the ordinary precautions against settlement taken by a competent builder will suffice. As no fire-place is permissible in an observatory because of the disturbing currents of air to which fires give rise, special precautions must be taken to protect the building and its contents against damp, and the consequences thereof. In heavy clay soils clear away the soil all around the outside of the observatory by making a trench, say Io feet wide and 4 feet deep, and fill up the excavation with broken bricks, coarse gravel, or other hard porous material. Provide by suitable gutters and pipes, that all rain-water falling on the observatory shall be carried away to a distance as quickly as possible.

Details of the Structure of the Observatory.-Fig. I. represents the ground plan and Fig. 2 the elevation of the Bedford Observatory. The external dimensions were about 35 feet by 13 feet 6 inches. The building was divided into two apartments: (I) an equatorial room, circular, and 15 feet in diameter on the inside; and (2) a transit-room, 17 feet by 12 feet on the inside, and 10 feet

$x$ A rock foundation is not necessarily the most stable possible, and some authorities deem a sandy substratum best. 
high. At Bedford the transit room contained a transit circle and a transit instrument, with a clock so placed that it could be used with either, as wanted; but an ordinary amateur will only need to have one meridian instrument, and the surplus space may advantageously be partitioned off to form a calculating-room, or the

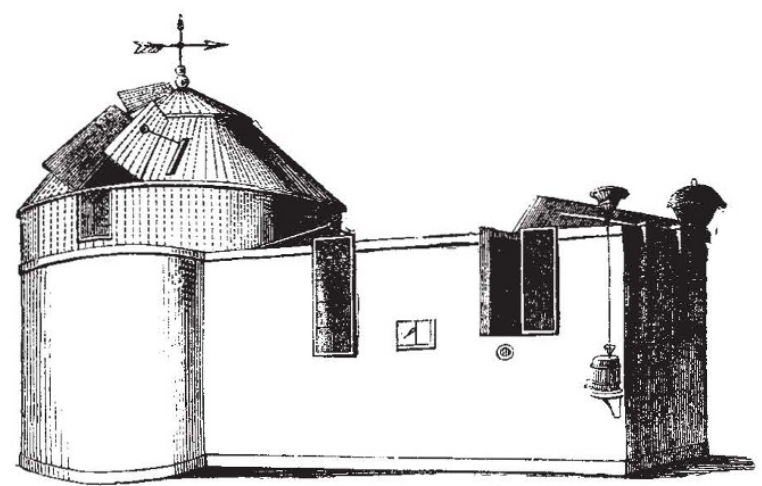

FIG. 2.-Elevation of the Bedford Observatory.

space may be used as an ante-room, and the entrance door put there, and not on the north side, as at Bedford.

It will now be convenient to describe the several parts of an observatory more in detail.

The Equatorial Room.-The equatorial being the principal instrument in every amateur's observatory, the provision made for its accommodation deserves attention first. It is not an uncommon practice to arrange that the floor of the equatorial room shall be 2 feet or 3 feet below the level of the adjoining room, and where a large equatorial is worked with a small transit instrument used merely for setting the clock, and economy and difficulties of site have to be considered, a sunken equatorial room may be unavoidable. But all the same the practice is highly inconvenient and ojectionable. An observer should be able to move rapidly from one part of his observatory to another in the dark, and without having to think of steps up or steps down. Moreover, in order to secure free internal ventilation nothing more substantial than a green baize curtain should separate the equatorial room from the transit room, and it is obviously not safe to use such

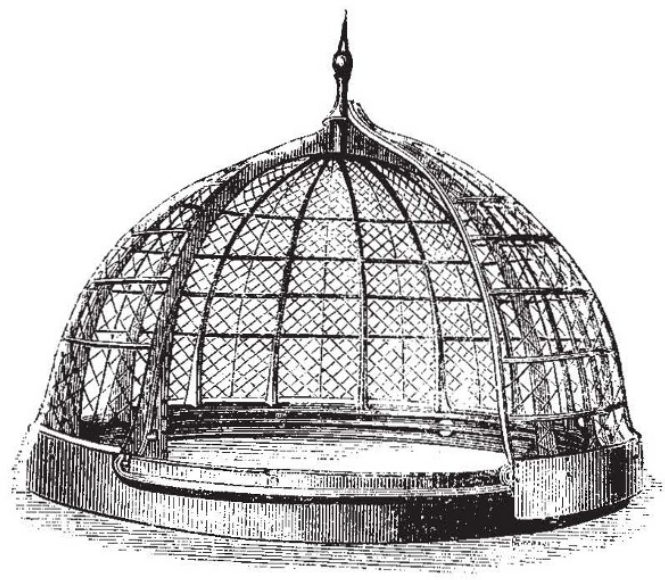

FIG. 3.-Diagram showing ribs of a dome intended to be covered with copper or sheet iron.

a curtain where it will conceal a difference of level of 2 feet or more.

Fig. I contemplates an equatorial of what is called the "English" form, with two separate piers for the support of the polar axis; but this construction of equatorial has become almost obsolete, owing to its numerous practical disadvantages, and the "German" form, with one pier and pillar, centrally placed, is now all but universally used, at least by amateurs.

The construction of a roof for an equatorial room (technically called the "dome," whatever may be its precise form) is a great crux to the intending builder of an observatory. Theoretically the hemisphere is the proper form, and roofs truly hemispherical are occasionally met with; but they are extremely troublesome and expensive to make, and can only be tackled by professional engineers.

Fig. 3 represents the skeleton framework of such a dome of large dimensions, before the sheet copper, or other material to be employed in covering it, has been been put on. Of late years, especially for large observatories, "drum" domes have come much into use as comparatively easy to construct, and capable of being made strong and watertight; but they offer much resistance to the wind, and architecturally are bound to be ugly.

For the purpose of protecting the smaller sizes of equatorials, say those from 4 inches to 7 inches in aperture, a polygonal dome is recommended. Or, in the case of equatorials of the smallest size, say from $2 \frac{1}{2}$ to 5 inches, the roof of the equatorial room may be flat, and arranged to open by sliding it to one side. Such a sliding roof should not be quite mathematically flat but should have a slight inclination, to throw off the rain.

Whatever be the form of the dome chosen the problems,

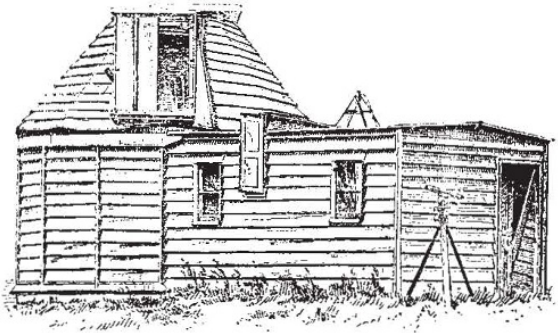

Fig. 4. - Wooden Observatory erected at Eastbourne in 1854.

how to uncover a slit in it, and how to move the whole of it, are matters which require in all cases careful consideration. Where the dome is a large one, say more than 12 feet in diameter, the shutters which close the slit should slide. They may slide laterally on a suitable staging (as in Fig. 4), or they may slide up and down. The latter is a very convenient expedient, especially when the observatory is to be erected in a situation exposed to strong winds, or when the telescope is to be much used on the sun; for the observer can open just so much space as will uncover the whole aperture of the telescope, and can keep himself and the greater part of his telescope protected from the direct impact of the wind, or the direct rays of the sun, as the case may be. When arranged in the best form the shutters will be three or four in number, each protecting a third or a fourth of the slit, measured vertically. Each shutter must have its own rabbet, and its own ropes and pulleys, in order to enable the observer to open at one time only so much of the whole slit as is necessary to enable him to scrutinise the particular portion of the heavens which he desires to examine. The advantage of thus being able to shelter himself and his telescope will soon be appreciated in windy weather, or under a meridian sun by the owner of an observatory fitted with sliding shutters.

Another important matter is the question of the bearings on which a dome is to be mounted. Large domes can only be made to move with facility by the aid of mechanical appliances which are often in practice both complex and cumbersome, and needing much muscular effort on the part of the person who has to move the 
dome. Where the weight of this does not exceed a ton, a set of grooved wheels running ina concave wall-plate of iron generally works well. For weights beyond this, special mechanical appliances must be used, which it is foreign to my present purpose to treat of. On the other hand, light domes--by which is meant domes up to, say, half a ton-are best dealt with by being mounted on iron balls (cannon balls in fact) travelling on a circular wallplate, and kept in place by an upper plate, the arrangement being such as is indicated in Fig. 5 .

The ironwork may be simplified in character and lessened in weight if the upper plate, which in Fig. 5 is, like the lower one, a solid casting, is replaced by two detached rails about an inch square in section and placed about 3 inches apart. The balls need only be three in number where the diameter of the dome does not exceed ro feet. If the diameter is greater than that a fourth ball may be desirable in order to distribute better the weight, and lessen the risk of the framework of the dome being strained. The diameter of the balls may be 4 or 5 inches (say 24-pounder or 32-pounder balls), and the more truly spherical they are the less the friction, and consequently the less the muscular effort, required to impart motion to the dome; and to this it may be added the less likely are the balls to approach one another after being some time in use and so in a sense dismount the dome. When this does happen the dome must be slightly prised up by means

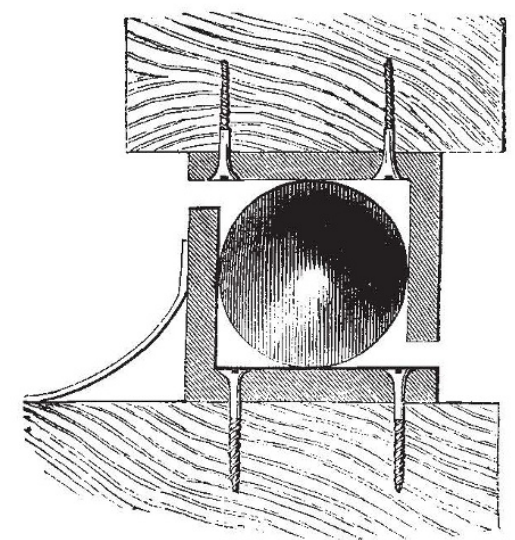

F1G. 5.-Section of beas ings for a dome (Bedford Observatory).

of a lever or jack, and the balls separated and set at a distance from one another of $120^{\circ}$ or $90^{\circ}$, according as there are three or four of them.

Where the dome is a light one, mounted on cannon balls, motion may be imparted to it by the simple process of pushing a long and strong handle which descends from the roof to a sufficient distance towards the floor; in other words, which is 4 feet or 5 feet long. Where a handle of this sort is used it should be affixed to the dome by strong screws or bolts, exactly opposite the shutters which cover the main opening, because when so placed the observer can grasp the handle and bring the openings exactly to that part of the heavens to which he has pointed his telescope, and can be sure that he has done so. In this facility of being able to watch how far the dome is moved resides the great advantage of the fixed handle; its disadvantage is that the observer in moving the dome has to follow it himself by walking around on the floor. To obviate this inconvenience, such as it is, some prefer a fixed wheel permanently attached to some one place in the wall of the observatory, and having cams in its periphery to catch suitable pins attached at short intervals to the inside circumference of the revolving dome.

Whatever may be the form of the dome, it is evident that in plan it must at the bottom be circular, and that the wall-plate must be circular also, and of the same dimensions. But the plan of the equatorial room, as regards its walls and floor, is another question. Where the room is large, say I 5 feet or 20 feet, or more, in diameter, it will be best that it also should be circular, or perhaps octagonal. Where, however, the dome is not more than 12 feet across, and consequently the whole establishment is on a small scale, there are great advantages in making the equatorial room square. In such a case the corners will be found very useful for various purposes : for instance, in one a desk or writing-slab may be fixed; in another, the clock; in a third, a lamp; whilst the fourth corner may take a chair or a stool. In other words, the corners become available as places of refuge for things and persons whilst the observer is turning the dome round from one part of the heavens to another. Moreover, the cost of building a square room is less than the cost of building a polygonal one, because the difficulty is less, be the material brick or wood. If wood is employed for the walls of an observatory, it will in all cases be desirable to place the frame on a dwarf wall of brickwork rising at least 2 feet above the general level of the ground.

The floor must be supported on joists, trimmed so as to form square frames around the piers which are to carry instruments. This will enable the floor-boards to be fixed firmly, yet quite clear of the piers, and will prevent tremors, caused by persons passing over the floor, being conveyed to the piers, and so to the instruments. A free circulation of air must be secured by means of small brass ventilating gratings suitably disposed around the floor near the walls.

Making due allowance for the different purposes for which it is to be used, many of the remarks just made with respect to the equatorial room will apply also to the transit room. The main part of the roof is a fixture, but an opening about I foot 6 inches wide has to be made right across the top, and to be continued into the north and south walls from the eaves downwards towards the floor, so as to enable the observer to sweep the meridian with the transit instrument from the south horizon through the zenith to the north horizon. The openings must be protected by shutters, which may either slide or lift. For large observatories Grubb has devised a form of balance shutter which swings, and is said to work well.

In cases where the top transit shutter, which constitutes part of the roof, is in the form of a flap and lifts, it must be counterpoised by a weight or weights travelling up and down inside the room. The vertical shutters must be treated as casements, and be fitted with handles and fastenings accordingly. The remarks made in speaking of the equatorial room as to the advantages offered by sliding shutters or sashes, apply equally to the case of sliding shutters for a transit room.

Light should be obtained for an observatory by independent windows, and not, as in Fig. 2, by panes of glass inserted in the shutters; for glasses are very apt to get broken by the constant moving of the shutters.

The transit instrument as such I need not describe in detail, but it may be worth while to show how a transit instrument is mounted where space is no object, and the instrument is intended for the determination of Right Ascensions rather than for the commonplace purpose of setting a clock.

The transit instrument at Bedford consisted of a telescope of $3 \frac{1}{2}$ feet focal length furnished with an object-glass whose aperture was $3 \frac{1}{4}$ inches; the telescope was supported by broad cones forming an axis 28 inches long, the pivots of which rested on covered Y's offering a surface of polished Brazilian pebble an inch in bearing, and which (owing to their bases being hemispherical and working in corresponding sockets) held their proportionate weight, as well as ensured the axis of the pivots being always strictly in the same right line. The Y's 
were placed on improved chucks whose azimuthal and vertical motions were effectually secured from dust and injury, and left the shoulders of the pivots just sufficient room for moving without friction ; the Y's were morticed upon 2 piers of Portland stone rising 5 feet 7 inches above the floor, and which with their bases weighed a ton each. The axis of the instrument was perforated at one end in the usual way for the admission of light from a lamp at night, but it also contained a contrivance for regulating, by means of a milled head on the telescope tube, the light falling on the wires; and there was, moreover, a rackscreen to the lamp for the same purpose. In the optical focus were five principal vertical wires (besides two for the Pole-star) crossed by one horizontal wire; with a slide and divided scale for bringing the axis of the eye tubes exactly over the respective wires, and thereby destroying parallax. This part of the tube was also fitted with a simple means for adjusting the eyepiece to the solar focus, and for taking out the frame bearing the spider lines in case they needed examination or repair. For setting the telescope the eye-end was furnished with two circles, 6 inches in diameter, each provided with a level and showing altitudes and zenith distances. But it is strongly recommended that such circles should in all cases be graduated and adjusted so as to show declinations. ${ }^{1}$

Setting circles attached to the eye-ends of telescopes are so extremely convenient for approximate settings that it is a matter of surprise that they are not more generally used. They are thought to have been invented by Troughton, and to have been first applied in 1816 to the Greenwich transit instrument. As to this, Smyth has a note as follows:- "Mr. Jones lent me a note-book of the

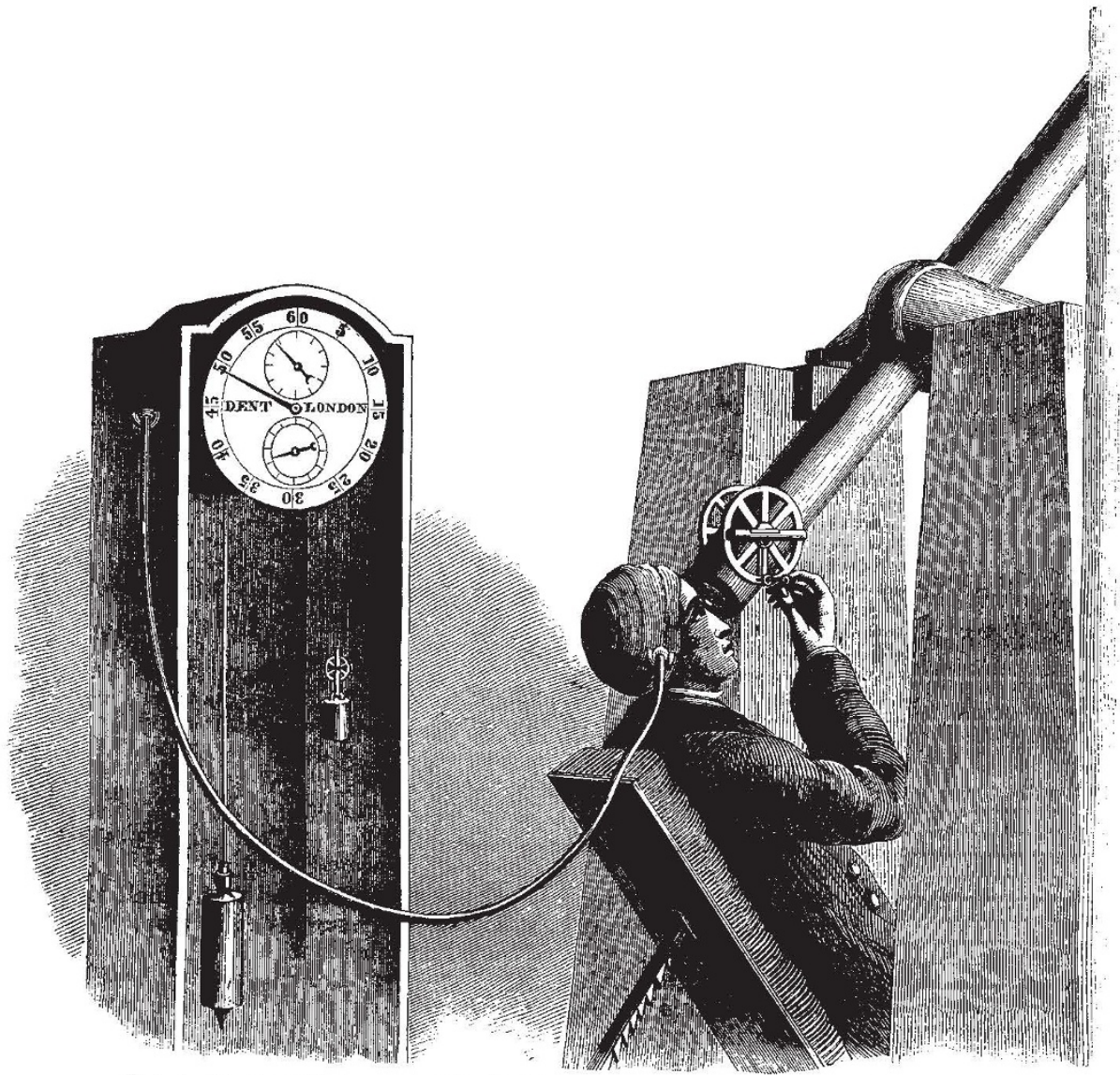

FIG. 6.-The transit instrument of the Bedford Observatory, with observing chair and clock.

late Mr. Walker, of Eidouranion memory, in which he describes a visit he made to the celebrated Jesse Ramsden in 1780 ; and mentions that he was shown an ingenious mode of elevating a transit instrument by a circle of about 3 inches diameter and a level at the eye-end. The vernier fixed and the circle with its attached level movable. To this statement is the sketch of a telescope so fitted, the accompanying portion of which I traced."

Meridian Mark.-This is an accessory to the transit instrument, so useful and so convenient that it is a matter of surprise that a meridian maris is not more generally provided in connection with transit instruments. affords by day, and, if illuminated, also by night, a means of verifying the meridian adjustment of the transit instrument. Fig. 8 represents the meridian mark used in connection with the Bedford Observatory. A plate of brass about 4-Ioths of an inch thick, 5 inches long, and 3 inches wide was fastened by four screws, passing through its corners, to a stone, into which four brass sockets to receive them had been made fast by molten lead. On this plate it was arranged that another of the same thickness should slide; this was $3^{\frac{1}{2}}$ inches long by $\mathrm{I} \frac{1}{2}$ inches broad, and was attached to the former by dovetailed side-pieces, and was capable of being adjusted by two long screws pressing against its ends. In the sliding plate there were four slots to receive four capstanheaded screws, by means of which the sliding-plate could be firmly made fast to the fixed plate after the mark had been duly adjusted to the meridian. This done, the end screws were withdrawn to prevent the possibility of their ${ }^{2}$ If information is needed as to how this is to be brought about reference may be made to Challis's "Lectures on Practical Astronomy," p. 26. 
being tampered with and the mark displaced from the meridian. On the sliding plate there was soldered a square piece of silver exhibiting a well-defined black cross, the centre of which was to mark the actual meridian. As this cross taken by itself hardly afforded sufficient vertical length for comparing the wires of the transit a small circle of silver (with a black dot in its centre) was placed above the cross as an auxiliary mark. This silver circle, like the larger silver plate below, was capable of lateral motion by means of capstan-headed screws which

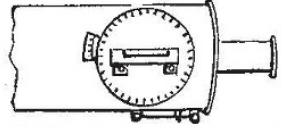 \\ FIG. 7.-Setting circle devised by Ramsden.}

could be removed when the dot had been brought exactly over the cross below. The stone to which the mark was fixed was firmly morticed into a dwarf pier, to guard against lateral movement, and the whole superstructure was firmly bedded on a solid substructure sunk into the earth. It is of the utmost importance to guard against settlements likely to cause any lateral movement, for it must be remembered that with a 5o-foot radius a displacement of about 3-10ooths of an inch is equivalent to one second. The remaining and important part of the arrangement at Bedford was a 4-inch lens of $49 \frac{1}{2}$ feet focus, being exactly its distance from the diaphragm. This lens was mounted in a brass collar, and having been attached by screws to a plate of cast-iron, was let into the wall of the transit window in a line with the transit instrument and the meridian mark. It is evident that the rays of light from the meridian mark become parallel after passing through the lens, and that the diaphragm can therefore be viewed through the telescope of the transit instrument as adjusted to solar focus. Another consequence of the rays being rendered thus parallel, is that no parallel motion of the transit axis would cause a change in the place of the object seen, so that the meridian is a line drawn from the diaphragm through the axis of the lens; and provided that these two points remain rigidly permanent, they offer all the advantages of a very distant meridian mark. And after all, a distant mark when obtainable can still be used as a check to the home mark. It will often happen that an observer will be able to find at the distance of a mile or two, or even of several miles, some well-defined line or point-e.g. a window sash, or the pinnacle of a church, or a piece of squared stone, which will serve him as a meridian mark for the simple reason that it lies in the meridian of his transit instrument.

Clocks.-A clock is a very important article of furniture in every observatory.

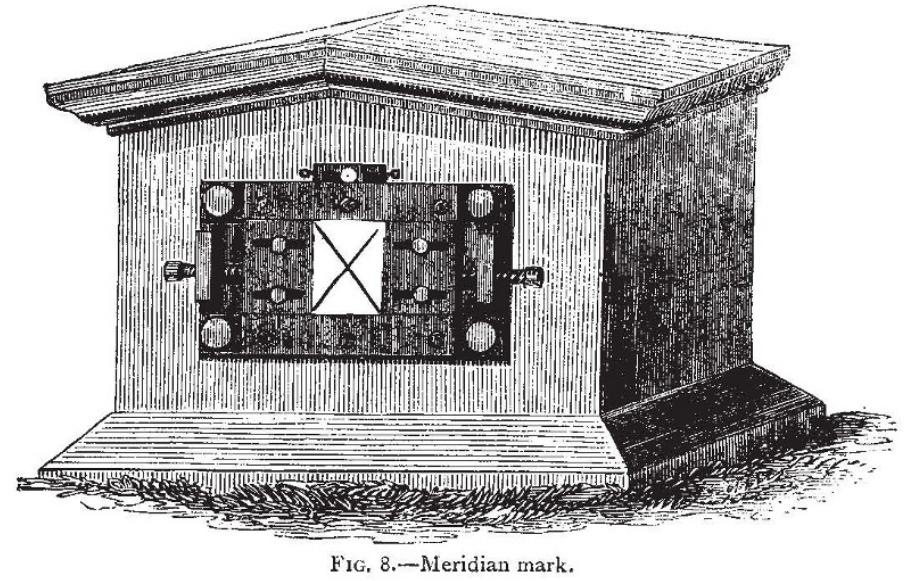

Whilst a proper sidereal clock showing twenty-four hours is what an amateur should have, he can very easily make shift with a much less pretentious time-piece, especially if his equatorial is provided with the best modern form of driving clock which only requires to be set once, or occasionally, during an evening's work. Indeed all that is essential in such a case is really a good dining-room clock (with its pendulum adjusted to sidereal time) which once set at the commencement of an evening by means of a transit instrument can be depended upon to maintain a tolerably even rate for half a dozen hours. The price of sidereal clocks for observatory purposes has been much reduced of late years, and from $20 l$. to $30 l$. will now command a fairly good one.

Where an observatory includes a transit room the clock should of course be placed so as to be visible both to an observer sitting at the transit instrument and facing the direction in which transits are most usually taken (that is, for the northern hemisphere, south) and also visible to an observer working with the equatorial. This desirable combination makes it expedient that the equatorial room should be at the west end of the buildings; but local reasons connected with the site of the observatory may not always render this possible.

For the clock there should be provided a stone pier constructed and isolated with much the sarne precautions as those already suggested in respect of the piers prepared to carry the telescope.

On the top of the clock case there is sometimes placed a "Hardy's noddy." This is a small and sensitive inverted pendulum inclosed under a glass bell and standing on a frame provided with three adjusting screws to level it. The use of the noddy is to discover whether the pendulum of the clock imparts any motion to its supports. But this is a refinement with which in a general way amateur observers need not concern themselves.

Meteorological Instruments. - Although an astronomical observatory is one thing and a meteorological observatory is altogether another thing, yet every astronomical establishment should be provided with a few of the more ordinary meteorological instruments, even though their owner does not profess to be a meteorologist. All astronomical observations are in a measure affected by changes in the temperature and humidity of the air; consequently, a self-registering maximum and minimum thermometer, a hygrometer, and a rain-gauge should be regarded as indispensable accessories to every observatory. No doubt, also, the desirability of having a barometer will naturally suggest itself, though its astronomical usefulness is very small indeed--by which I 
mean that changes of pressure only require to be taken account of in the very exact instrumental observations carried out in first-class observatories. It is also important that a respectable weathercock should be in sight, for the direction of the wind exercises, as is well known, a potent influence on the condition of the air, as revealed by the scrutiny of a celestial object through a telescope.

A good "Six's" thermometer is quite good enough for general purposes, although not a self-registering instrument of the highest scientific precision. As a hygrometer, "Mason's wet-and-dry-bulb" instrument leaves nothing to be desired.

The one special precaution of a meteorological character to be taken in connection with all astronomical observations, whether made in an observatory or in the open air, is that equality of temperature should be secured everywhere. Whilst the due ventilation of the observatory should at all times be provided for, it is absolutely essential, in order to insure good results with every kind of instrument, that all doors and windows should be thrown open, so as to obtain a free current of air everywhere for fully half an hour before observations are to be begun; in hot summer weather, indeed, a longer time will generally be found necessary. The object of these precautions is obvious enough : it is to insure the inside air and the metal of the instruments being cooled down (or, as it may sometimes happen, being warmed up) to the temperature of the external air. In order to learn whether this equality exists, every observatory should have a thermometer outside as well as inside. The former should be hung on the north side, away from the sun, and, if possible, not actually in contact with the observatory itself.

G. F. CHAMBERS

\section{( $T$ o be continued.)}

\section{NOTES}

WE learn with much pleasure from Science the election of Prof. E. S. Holden to be President of the University of California, and Director of the Lick Observatory. Prof. Holden's resignation as Director of the Washburn Observatory at Madison, Wis., takes effect on January I next. His appointment as Director of the Lick Observatory will hardly be a matter of surprise to those who are aware that, as consulting astronomer, he has virtually had the direction of the work as it has progressed, visiting the site on Mount Hamilton in 1881 , and again in 1883 and 1884 . Very happily the choice both of the Lick trustees and of the regents of the University has fallen upon Prof. Holden. It is understood that, in his letter of resignation to the regents of the University of Wisconsin, he strongly urges the name of Prof. W. A. Rogers, of Harvard College Observatory, as his successor.

THE wealthy American, Senator Stanford, proposes to establish a Californian University. He intends to give to it, besides estates worth 5,300,000 dollars, a donation in money increasing its endowments to $20,000,000$ dollars. The University will be located at Palo-Alto, thirty miles from San Francisco, and is apparently to be modelled somewhat after the plan of the Johns Hopkins institution.

THE prospectus has been issued by Herr Fischer, publisher, of Jena, of a new scientific periodal entitled Zoologische Farhbücher: Zeitschrift für Systematik Geographie und Brologie der Thiere, which is to be brought out under the editorship of Dr. J. W. Sprengel, of Bremen, Notwithstanding the vast number of scientific journals, both author and publisher think that this department of science does not receive the attention which it deserves. It is not excluded, they say, from scientific periodicals ; but communications relating to it appear more or less as strangers by the side of others. The new periodical will be wholly devoted to this class of subjects. In the first section the papers will, for the most part, be of a higher kind than the mere description of new species, except those for which no special journal exists. The geographical section will contain studies on the distribution of all kinds of animal and vegetable life, and special attention is promised to the biological section. Contributions will be received in German, French, English, and Latin. The periodical will appear quarterly, each four issues making a volume.

THE snccess of the last electrical exhibition at the Paris Observatory was so complete that the International Society of El ectricians is preparing another for next spring.

A General meeting of members of the French Association for the Advancement of Science has been summoned to approve of the fusion with the Sociéte Française. Lectures and meetings will take place this year under the patronage of the united societies as a single body.

TrEe well-known electrician, Dr. James Moser, who was working for some time at Prof. Guthrie's laboratory, has been appointed as privatdocent at Vienna University.

THE Colonial fisheries are to form a prominent feature at the Indian and Colonial Exhibition which is to be held next year. The Aquarium will be considerably enlarged, and special tanks are now being prepared for the reception of the various fish from the Colonies. A tank of colossal proportions is to be allotted for the purpose of exhibiting turtles in large numbers which will be despatched from India together with other specimens in the early part of next year. We do not yet know what fish are to be forwarded from the various colonies, but the utmost care will have to be exercised and the most perfect arrangements made in order to provide for their various necessities. The collection promises to be one of great interest and value, although its success all depends upon how the fish withstand the long journeys to which they will be subjected.

TOWARDS the end of October the remarkable sun-glows were again seen at Stockholm. In the western horizon a yellow cloud-bank, strongly illuminated, appeared behind a number of tiny clouds, greyish in colour, the sky above the former, to a height of about $45^{\circ}$, being lurid, entirely colouring the clouds. Later on in the evening the glow imparted to the edges of the clouds the most remarkable reflections of colour, varying from ochre to yellow, violet, and pink, with shadings of blue. At times the higher-lying clouds formed most remarkable formations. It seemed that the glow was situated between cumulus and cirrus clouds.

ON October 2I, at about 5 a.m., a brilliant meteor was observed at Skaadö, on the south-east coast of Norway. It appeared first near the zenith, and describing a circle of about $70^{\circ}$, disappeared in the south-west, about $20^{\circ}$ above the horizon. In spite of the sky being covered with clouds, and its being still dark, the country around was lit up as in daylight, objects being clearly discernible at a great distance. As no sound or explosion was heard, it is assumed that the track of the meteor lay in the upper parts of the atmosphere.

Some Thames trout are being spawned at Sunbury by the Thames Angling Preservation Society, who are doing their utmost to replenish the stock of this fine species of Salmonidæ, which, unhappily, have now become a rarity. The ova will be incubated by the National Fish Culture Association, and the fry will ultimately be deposited in one of the Thames nurseries.

THE Catalogue of the Library of the Royal Society of Tasmania is a considerable volume; and it is a matter of some surprise to find that men of science in this distant colony have 